\title{
Drug policy at the margins: the case of growth hormone replacement for adults with severe growth hormone deficiency
}

\section{Are current standards of evidence always appropriate when making the decision to subsidise treatment?}

\section{the}

he Pharmaceutical Benefits Scheme (PBS) provides the Australian community with subsidised access to medicines. Decisions about which medicines are listed on the PBS are made by the Minister for Health and Ageing, on the advice of the Pharmaceutical Benefits Advisory Committee (PBAC) - an independent statutory body charged with assessing the clinical benefit and costeffectiveness of the medicines under consideration.

While Australia is considered to be a world leader in such decision making, interpretations of data surrounding efficacy and cost-effectiveness are often complex and contested. The recent decision by the PBAC not to subsidise recombinant growth hormone (somatropin) for adults with severe growth hormone deficiency (GHD) is a case in point.

Growth hormone $(\mathrm{GH})$ is best known for its role in stimulating growth in children, but it continues to be produced throughout adult life, when it plays a critical role in regulating metabolism and the functional integrity of tissues and organs. Adult growth hormone deficiency (AGHD) - not to be confused with idiopathic growth failure during childhood — can be the result of congenital pituitary abnormalities or acquired loss of pituitary function resulting from tumours, irradiation, intracerebral haemorrhage and head injuries. The clinical picture is characterised by insulin resistance with atherogenic lipid profiles, central adiposity, muscle loss and weakness, osteoporosis, fatigue, demotivation and depression, and a twofold increase in premature cardiovascular mortality. ${ }^{1}$

Over the past 20 years, trials and clinical experience with biosynthetic $\mathrm{GH}$ replacement therapy in children and adults have provided substantial evidence that this therapy is safe and well tolerated, and the Therapeutic Goods Administration (TGA) has registered GH for the treatment of adults with severe GHD. GH replacement in adults with GHD has been shown to increase lean body mass and bone mass, reduce fat mass, improve physical function, improve cardiovascular risk profile, improve mood and energy, and reduce the use of health services. ${ }^{1,2}$ While, for reasons that will be discussed below, there is limited evidence of the effects of GH replacement on mortality, extrapolation from the improvement in lipid profile alone would suggest that cardiovascular mortality may be reduced as a result of $\mathrm{GH}$ replacement.

Consensus guidelines from leading international professional bodies have uniformly endorsed $\mathrm{GH}$ replacement therapy for adults with severe GHD caused by
Wendy L Lipworth MB BS, MSc, PhD, Postdoctoral Research Fellow

Ken Ho MD, FRACP, FRCP, Professor of Medicine ${ }^{2}$

Ian H Kerridge BMed(Hons), MPhil, FRACP, Director ${ }^{3}$

Richard O Day AM, MD, FRACP Director ${ }^{4}$

1 Australian Institute of Health Innovation, University of New South Wales, Sydney, NSW.

2 Centres for Health Research, Princess Alexandra Hospital, Brisbane, QLD.

$\mathbf{3}$ Centre for Values, Ethics and the Law in Medicine, University of Sydney, Sydney, NSW.

4 Clinical Pharmacology and Toxicology,

St Vincent's Hospital, Sydney, NSW.

w.lipworth@ unsw.edu.au

doi: 10.5694/mjall.11572

\footnotetext{
ditiph
} improvements in quality of life (which was the main variable used to justify the submission) with $\mathrm{GH}$ replacement in adults, and limited evidence of costeffectiveness. There are, however, a number of features of AGHD and GH replacement therapy that might have weighed against a more favourable decision, despite the evidence of benefit described earlier.

First, existing data about the effectiveness of GH replacement do not distinguish consistently between severe AGHD (for which subsidisation was requested) and milder deficiencies. To make matters worse, two of the pivotal studies presented to the PBAC used diagnostic criteria for AGHD that would have led to a number of false-positive diagnoses of GHD, thus skewing the results in the direction of non-efficacy. ${ }^{6,7}$

Second, even if trials are designed appropriately, assessment of the physiological efficacy of $\mathrm{GH}$ replacement is made difficult by the rarity of GHD in adults, which curtails the ability to obtain hard therapeutic end points (eg, mortality or fracture reduction). It is also made difficult by the fact that GH acts on several body systems, defying the use of a simple metric to measure efficacy, and by the practical difficulties of conducting 
long-term placebo-controlled evaluation of a medication requiring daily injections. ${ }^{8}$

The assessment of quality of life in conditions like GHD is also extremely difficult and highly dependent on the methods used. Thus, while some trials of GH have reported improved quality of life, ${ }^{1,2}$ different tools were used to assess quality of life in different life circumstances and in different populations. Matters are complicated further by the fact that quality of life is difficult to assess in young adults with childhood-onset GHD, whose positive experiences of treatment might be masked by negative childhood experiences of daily injections. ${ }^{9}$

This places patients with AGHD and the clinicians who care for them in a difficult situation. For, while there are good reasons on theoretical, physiological and epidemiological grounds for why adults with severe GHD (or at least subsets of such patients) would be likely to benefit from hormone replacement therapy, it is difficult to provide data showing sufficient benefit - let alone costeffectiveness - to justify its inclusion on the PBS. In this regard, adults with severe GHD are not alone, and such difficulties are likely to increase for patients with other conditions, as diagnoses become increasingly finegrained, and prognostic markers become more discriminatory, making it increasingly difficult to conduct the research needed to unequivocally demonstrate clinical benefit and cost-effectiveness.

So, what are we to do in such situations, where it seems difficult, if not impossible, to generate the kind of evidence that is required by the PBAC? First, we need to acknowledge that, irrespective of our view of particular decisions, the PBAC makes its decisions on the basis of clearly articulated standards of evidence, as outlined in its Guidelines for preparing submissions to the Pharmaceutical Benefits Advisory Committee. ${ }^{10}$

But we do need to question whether or not these standards of evidence are appropriate. If we decide that existing standards are appropriate, and should not be adjusted in situations where perhaps the "best" evidence stems from physiological reasoning, clinical experience or limited epidemiological research, then we need to accept that there will be situations in which access to particular goods and services will be restricted because of our requirements for particular standards of evidence and our concerns about opportunity cost (ie, the money spent on one intervention being therefore not available for another). If, on the other hand, we decide that compromises should be made on moral grounds - because we recognise that the evidence that we usually require is not (and may never be) available, or because treatment of this particular population is justified by reference to an important moral principle such as equity or concern for its vulnerability then we need clear processes and standards for making such exceptions. With this in mind, we would suggest the following approach to PBAC decision making in situations where standards of evidence have not been met.

First, the sponsoring body (commercial, consumer or professional) needs to do the best possible job of gathering further data, or reanalysing data to identify patients who are most likely to benefit. Where such evidence is not available, the PBAC could either recommend subsidisation, subject to evidence development, or refuse to recommend coverage until evidence has been obtained. If it proves to be impossible to gather this evidence, then the PBAC needs to decide whether it is willing to adjust its usual evidentiary standards with the goal of achieving greater equity, even if this occurs at the expense of (demonstrable) efficacy and/or cost-effectiveness. Whatever it decides, the PBAC then needs to be explicit about how it came to this decision, so that those concerned with the decision are aware of the moral compromises that have been made.

Unless sponsors and regulators can agree on how pharmaceutical agents can be assessed where high-quality
Growth hormone acts on several body systems, defying the use of a simple metric to measure efficacy evidence is lacking, and where characteristics of the disease or patient population make it unlikely that highquality evidence will ever be attainable, PBAC assessment will remain too blunt an instrument to cope with increasing subcategorisation of disease and with increasing complexity of pharmacotherapies; and unacknowledged, systematic inequities will become an increasingly prominent feature of our pharmaceutical landscape.

Competing interests: Ken Ho has been on an Eli Lilly advisory board and has been a consultant to Pfizer. Richard Day has provided occasional advice to Merck Australia about rofecoxib and etoricoxib.

Provenance: Not commissioned; externally peer reviewed.

1 Molitch ME, Clemmons DR, Malozowski S, et al. Evaluation and treatment of adult growth hormone deficiency: an Endocrine Society clinical practice guideline. J Clin Endocrinol Metab 2011; 96: 1587-1609.

2 Woodhouse LJ, Mukherjee A, Shalet SM, et al. The influence of growth hormone status on physical impairments, functional limitations, and healthrelated quality of life in adults. Endocr Rev 2006; 27: 287-317.

3 Ho KK; GH Deficiency Consensus Workshop Participants. Consensus guidelines for the diagnosis and treatment of adults with GH deficiency Il: a statement of the GH Research Society in association with the European Society for Pediatric Endocrinology, Lawson Wilkins Society, European Society of Endocrinology, Japan Endocrine Society, and Endocrine Society of Australia. Eur J Endocrinol 2007; 157: 695-700.

4 National Institute for Clinical Excellence. Human growth hormone (somatropin) in adults with growth hormone deficiency. Technology Appraisal 64. London: NICE, 2003 (reviewed 2006). http://www.nice.org.uk/nicemedia/ live/11504/32665/32665.pdf (accessed May 2012).

5 Pharmaceutical Benefits Advisory Committee. July 2011 PBAC Outcomes lst time decisions not to recommend. Canberra: Department of Health and Ageing, 2011. http://www.pbs.gov.au/info/industry/listing/elements/pbacmeetings/pbac-outcomes/2011-07/1st-time-decisions (accessed Oct 2011).

6 Underwood LE, Attie KM, Baptista J; Genentech Collaborative Study Group. Growth hormone $(\mathrm{GH})$ dose-response in young adults with childhood-onset GH deficiency: a two-year, multicenter, multiple-dose, placebo-controlled study. J Clin Endocrinol Metab 2003; 88: 5273-5280.

7 Hoffman AR, Kuntze JE, Baptista J, et al. Growth hormone (GH) replacement therapy in adult-onset $\mathrm{GH}$ deficiency: effects on body composition in men and women in a double-blind, randomized, placebo-controlled trial. J Clin Endocrinol Metab 2004; 89: 2048-2056.

8 Carroll PV, Christ ER, Bengtsson BA, et al. Growth hormone deficiency in adulthood and the effects of growth hormone replacement: a review. Growth Hormone Research Society Scientific Committee. J Clin Endocrinol Metab 1998; 83: 382-395.

9 Attanasio AF, Lamberts SW, Matranga AM, et al. Adult growth hormone (GH)deficient patients demonstrate heterogeneity between childhood onset and adult onset before and during human GH treatment. Adult Growth Hormone Deficiency Study Group. J Clin Endocrinol Metab 1997; 82: 82-88.

10 Pharmaceutical Benefits Advisory Committee. Guidelines for preparing submissions to the PBAC - December 2008. Canberra: Department of Health and Ageing, 2008. http://www.health.gov.au/internet/main/publishing.nsf/ content/pbacguidelines-index (accessed May 2012). 